\title{
Sentence Connexion and Global Text Structures: A Case Study of a Political Text: English Leader Article
}

\author{
Dieter Stein \\ University of Düsseldorf \\ Adriana Mattei \\ University of Naples
}

\begin{abstract}
The paper first gives a brief overview of the history and theoretical status of discourse analysis, or "text linguistics." The main body of the paper consists of a detailed analysis of sentence connexion, i.e. the logical relationship between sentences and larger chunks of text, performed on a newspaper leader article. The results of this local analysis are then related to the global organisation of text structure with components such as macro- and super-structure by way of interpreting them in terms of the psycholinguistics of global text comprehension. The analysis is supplemented by considerations of functional sentence perspective, topic management, and a characterisation of the macro-speech act as primarily subjective with the appropriate surface manifestations.
\end{abstract}

The purpose of the paper is an in-depth analysis of a political text, using that analyis to demonstrate the power of discourse analysis in the elucidation of the inner workings and structurings of a text. The emphasis is on sentence connexion and its relationship to global text structures, while briefly also considering related approaches to text analysis. The aim is to uncover what speakers and hearers, or writers and readers implement in terms of tacit knowledge-or textual competence-in creating what is felt to be a coherent and felicitous piece of discourse. The procedure will be to briefly introduce concepts of text linguistics and then move on to apply those concepts in a concrete in-depth analysis of a political text. Finally, since the analysis will be performed on a political text, a leader article from The Guardian Weekly, the question will be asked, what are the liriguistic specifics of such a text type. 


\section{A brief overview of text linguistics}

At the beginning must be a short digression on terminology: there are three terms: text, discourse, and conversation. In earlier literature the term text tended to refer to written language only, the terms discouse and conversation more to spoken language. These uses reflected specific research orientations or were connected with these terms, such as the term text used to be associated with the philology of written texts. The term discourse represented a more modern orientation oriented more towards spoken discourse. In the following exposition we intend the terms text and discourse to refer to both spoken and written language alike. They are used as synonyms. The term conversation, on the other hand, will refer to spoken language only. Therefore discourse analysis and text linguistics will be used interchangeably.

Discourse analysis or text linguistics is a new discipline. It arose as a full-fledged discipline in the 1960s, together with pragmatics and sociolinguistics as part of a reorientation of linguistics towards the linguistics of usage and the linguistics of the interaction of language with context. The more traditional paradigms like structuralism centered on the analysis of the word, whereas generativism focused on the sentence. If we conceptualize the build of language as a kind of pyramid, textlinguistics is the upward extension of the analysis of successively higher ranking linguistic units. At the bottom is the analysis of phonology, dealing with the minimal meaning distinguishing units of language, further up is morphology, dealing with the minimal meaning-bearing units of language, still higher up is syntax. For all these levels it is/was typical that there is a more or less finite set of units with rules for combining them to well formed structures. From this point of view it is natural to look for one higher level yet, looking for rules how sentences would combine to form well formed texts. One feature of this pyramid idea of the build of language is that the further up one moves, the more context sensitive, i.e. dependent on nonlinguistic information, the operation of rules for wellformedness becomes. For instance for phonology it is relatively easy to identify the rules which let us combine phonemes to wellformed words. It was the attempt of the generative enterprise to find similar language internal rules which would determine how morphemes would combine to form wellformed sentences. However, even within this language-internal approach it was getting increasingly difficult to specify purely language-internal rules for forming these higher ranking structures in syntax. A number of phenomena were discovered which were recalcitrant to an analysis in purely language-internal terms, like the case of some versus any which is dependent on unverbalized polarity expectations-a clearly extra linguistic factor.

It is, therefore, possible to identify two linguistics-internal sources of textlinguistics: the first is a dissatisfaction with purely language-internal terms of analysis. It was found that certain rules had to make reference to information beyond the individual sentence, both information in adjacent sentences and information in the context of use. The other motivation was the attempt to extend the analysis further up the pyramid of the build of language. It was natural to try to treat textlinguistics in the same way as the lower levels of language had been treated, that is to try and find rules for the combination of finite elements to wellformed structures. The main obstacle was the increasing context 
sensitivity of units higher than the sentence. This is why increasingly recourse had to be taken to a structured analysis of context and its interaction with linguistic units, a type of phenomenon that is typically dealt with by pragmatics. In other words the analysis of the whole text proceeded from an attempt to preceed language-internally to a more pragmatically oriented approach. It was the former approach that was more likely to be labelled textlinguistics, while the latter approach, the more pragmatically-based one, was more likely to be termed discourse analysis. But remember that these terms will now here be used interchangeably.

This first, more textlinguistic phase of linguistics tried to explain wellformedness in terms of the text by referring to surface features of the text only, it dealt with the analysis of "cohesion." The second, more pragmatically oriented phase of text linguistics includes, apart from the analysis of the interaction of verbal with nonverbal context, the representation of the content of both the text and of contextual information in our cognition. It tries to explain what goes on in the text in the way of information processing and information management as located in our minds. It tries to look at what linguistic expressions "do" in terms of instructing our mind to perform mental operations in a flow of information processing. This more modern, cognitively based version of discourse analysis deals with "coherence." So cohesion is more surface-oriented, coherence is more functional or mental representation based.

If textlinguistics as a full-fledged academic discipline with chairs and professors is a new phenomenon, there are certain facts about the use of certain texts which have long been the subject of analysis by neighbouring disciplines, especially literature, stylistics, and rhetoric. Rhetoric originated as a political pursuit in Greek democracies, it centered on the spoken art of language use as part of "persuasio." Later on it decayed into purely literary (written) stylistics (cf. Jens). Thus there was a very early association between politics and textlinguistics. In the Middle Ages rhetoric was part of the trivium.

The work done in literary analysis that is relevant under the heading of textlinguistics is best epitomized by the treatment of Coseriu, who views textlinguistics as a subdivision of literary analysis, or, the other way round, who views the analysis of literary text as the only worthwhile pursuit of textlinguistics. Following the notion of competence as elaborated by generative linguists, he would postulate a specific textformational competence which is relatively independent of the competence involved in mastering language specific sentence formation rules. Thus it would be perfectly normal for a person to have only a not quite perfect competence in a language but to have a perfect competence in textformation. Many literary figures who mediate between cultures and languages and who have written classics in the world of the novel may seem to justify Coseriu in his assumptions.

\section{Aim and methods of discourse analysis}

The key task of the linguistics of discourse is the explication of intuition that the text is a closed-off, self contained whole, a unit of its own, in the same way as grammatical analysis makes explicit the unconsciously functioning structure of grammar and syntax. 
Different stages of textlinguistics have given different types of answers to this question. As already indicated above in $\S 1$, two phases of textlinguistics can be distinguished. The first phase, analysing "cohesion," dealt with topics like Functional Sentence Perspective, logical connections between sentences, topic structure and proforms. This paper will start out with an analysis within the first approach, but will extend it to an interpretation of the results in terms of the second, coherence-based approach.

Since it would be foolhardy to try and demonstrate the full range of analytical instruments of discourse analysis in the context and the scope of this paper, we will limit ourselves to a very brief discussion of two very well-studied types of analysis, and, in $\S$ 3 to a detailed implementation of a third aspect, which will lead on to more modern, and cognitively-based dimensions of discourse analysis $(\$ 4)$ in a natural way.

\subsection{Coreferentiality and proforms}

A most obvious means of semantic coherence is the phenomenon that the same things get talked about, more technically speaking, the same object is being referred to again and again, although by different expressions: this is what is meant by coreferentiality of different expressions. The simplest case is when the same expression is being repeated, as in "the dog" ... "the dog." Since this is stylistically undesirable, pro-forms are being used, i.e. expressions which are different in form, but identical in meaning. Pro-forms are by definition coreferential:

the $\operatorname{dog} . .$. it ... the animal ... the little stupid thing ...

All of these expressions refer to exactly the same object meant in a concrete text. Only one of them belongs to the word class that is canonically assigned to this job of coreferring, i.e. pronouns. Many other expressions can function as pro- expressions. In the text under investigation, the following chains of coreferential expressions may be observed, by way of example:

Prime Minister ... his ... he ... $\phi$ (in muddied the water)

(note that $\phi$ can also be a proform!)

economic situation ... serious ... injury ... the rot ... the trouble ...

Another, related, but not identical, feature of semantic coherence is to be observed in the following example:

export ... import ... three-month period ... finished manufactures ... slump ... lobby ...

Obviously, these expressions are not coreferential, but only semantically related by virtue of belonging to the same semantic field: they share at least one semantic feature, a seme, in this case "having to do with economy." Semantic coherence is here constituted by seme recurrence, a special sub-case of so-called text-isotopies (Weinrich). It should be noted that these features of semantic coherence are far from constituting an exhaustive list 
of analytical work in this particular field of semantic coherence. For another, cognitively based theory see Beaugrande (Text, discourse and Process).

\subsection{Functional Sentence Perspective}

Another important traditional instrument of the analysis of discourse has for a long time been the progression of the information structure of the text, so-called functional sentence perspective (Garvin). It views communication as a progressive introduction of new information. This is the raison d'etre for most (non-phatic) communication in the first place. However, new information is not introduced out of the blue, but anchored in preexisting information. This leads to the division of information contained in the sentence as thematic (known) and rhematic (new) information. The rheme is the reason for uttering anything at all. To give the simplest-most example:

John bought a dog. It was very expensive. The price was ten times the price of a television.

"[A] dog" is the rheme, which is followed up on in the second sentence, where the former rheme now becomes the theme, the starting or anchoring point of yet more new information, i.e. that it was very expensive. In turn, the expensiveness, the rheme in sentence 2, now known information by the time sentence 3 is uttered, becomes the theme in sentence 3. This run-on transformation of new information as the starting point for yet further new information, is called "thematic progression." For a discussion of possible patterns of thematic progression see Gerzymisch. By way of an easier example from the text investigated, the second paragraph from the second sentence onwards can be analysed in terms of FSP as shown in Diagram 1.
Theme
(5) Imports
Rheme
rise

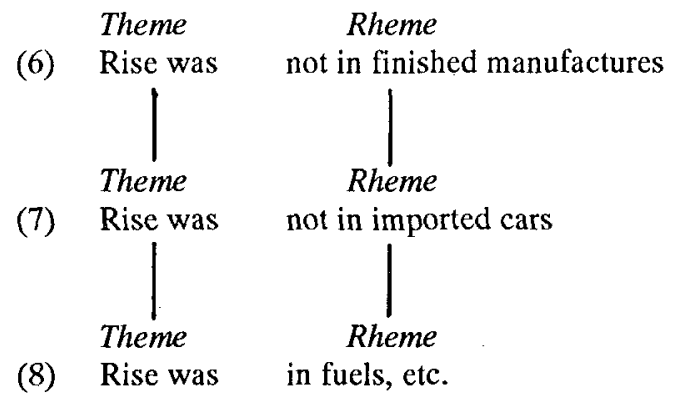

Diagram 1: Theme-rheme structure of paragraph II 
It will be noted that in the first sentence quoted a rheme is being introduced, which then serves as the theme for the following sentences, i.e. the theme stays the same, and there is no permanent turn-over of theme and rheme as in the made-up example above. The stability of the theme as in the analysed paragraph is another feature that contributes to textual stability and coherence. Functional sentence perspective will be taken up at a later point in the presentation.

\section{Connexion}

\subsection{Definition of connexion}

Connexion is best defined, at least initially, as logical relationship between adjacent propositions ("sentences"). The logical relationship is one of adversativity or contrast: the facts expressed in sentences 5 and 6 are in a contrast, marked by a conjunction at the beginning of the second sentence ("but"). To be a little more precise, the facts reported in ss. 5 and 6 are seen by the author of the text as in a contrast, and he wants us to share his opinion. This may sound easy enough, but consider the following sentences, taken from Allerton:
a) Holmes arrived late. Consequently they missed the train They nevertheless caught the train
b) Holmes arrived late; and so they missed the train but they caught the train
c) Because Holmes arrived late, they missed the train Although caught
d) Because of Holmes arriving late they missed the train Despite caught
e) Because of Holmes's late arrival they missed the train Despite caught
f) Holmes's late arrival caused them to miss the train did not prevent them (from) catching the train

Obviously there are different ways of formulating an invariant content, with connexion being defined only as the cases a, b, and $c$. There is in linguistic analysis a tendency to regard as peripheral meaning-and varying with different packagings- meanings other than propositional "kernel" meanings, such as FSP, or social and/or stylistic meanings.

Interesting theoretical problems are attached here: where does "sameness" of meaning end? How much of the meaning must be unchanged for the two propositions to be still considered the same? Is the meaning still the "same" if we pass from a proposition (containing a verb, which can be negated) to a nominalisation? These are problems to be dealt with by a more general linguistic performance theory of formulation (Antos), and which are also inherent in a number of widely-discussed linguistic problems. 


\subsection{Detailed analysis of text}

It will be seen that connexion between propositions exists also between clauses of individual sentences which have not been given individual indexes. For reasons of formal consistency number indexes have only been assigned to propositions which appear as sentences-i.e. between full stops-in the text. Exceptions are 3 which is treated as one sentence in its own right, as against the second clause of 20 , which is not, since it contains very subsidiary material. The second clause of 13 contains a parenthetical statement which is on a different level of the text. Relative sentences which postdetermine a nominal head do not fall within our compass.

Connexion has been defined as logical relationships between adjacent propositions. By way of a first approximation to the text we will start by identifying clearer cases of connexion between such adjacent propositions in the text, the discussion of cases where this adjacency criterion does not hold. This is why, by way of a didactic procedure, we will start in the middle of the text, with cases which show connexion between adjacent propositions.

The following is a list of cases of connection in the text where propositions are in connective relationships with their following proposition:

$\begin{array}{lll}\begin{array}{l}\text { two-three } \\ \text { five/six }\end{array} & \begin{array}{l}\text { constrastive } \\ \text { adversative }\end{array} & \begin{array}{l}\text { marked by } \text { and then } \\ \text { marked by } \text { but }\end{array} \\ 6 / 7 & \text { additivespecifying } & \text { marked by } \text { even } \\ 6 / 8 & \text { adversative } & \text { not marked } \\ 10 / 11 & \text { additivespecifying } & \text { marked by zero } \\ 10 / 12 & \text { contrastive } & \text { marked by now }\end{array}$

This could also be classed as having an element of temporality:

$\begin{array}{lll}12 / 13 & \text { additive specifying } & \text { not marked } \\ 13 / 14 & \text { additive specifying } & \text { not marked } \\ 13 / 15 & \text { contrastive } & \text { marked by quite simply } \\ 15 / 16 & \text { additive specifying } & \text { not marked } \\ 16 / 17 & \text { contrastive } & \text { not marked } \\ 19 / 20 & \text { additive specifying } & \text { not marked } \\ 19 / 21 & \text { causative } & \text { not marked } \\ 19 / 22 & \text { additive } & \text { marked by besides } \\ 22 / 23 & \text { additive specifying } & \text { not marked } \\ 22 / 24 & \text { causative } & \text { not marked }\end{array}$

This analysis turns up a number of interesting features which will be discussed in turn. The first interesting feature is the class of connective relationships. It will be seen that only a small subclass of possible connective relationships can be observed in this text, namely contrastive and additive specifying, representing the great majority of cases. The last paragraph contains, in addition, two causative relationships. This specific distribution of connective relationships is certainly a fact that has to be related to the type of text (see below). 
The next important point to note is that by no means all sentences in the text are related to their adjacent sentences on both sides by connective relationships. It will be seen that some sentences do not enter into connective relationships with their following sentences. Examples are sentence 7, which does not enter into connective relationship with its adjacent sentence 8 , or sentence 11 , which does not enter into connective relationship with sentence 12. Further examples are sentence 14 and sentences 20, 21, 22, and 23 . These sentences kind of dangle in the air, a finding that will have to be taken up in the context of the discussion of macrostructure of the text.

If some sentences are dead ends, connectively speaking, other sentences are higher up in the air than the ones previously discussed. Sentences $1,4,9$, and 18 seem to have a specific status in that they do not enter into a connective relationship with their respective following sentences $(2,5,10,19)$. Rather, on closer inspection they have connective relationships with the whole of the following sentences within that same paragraph. In other words they seem to have a very elevated status in that they as individual sentences enter connective relationships with whole groups of sentences. In fact the reading of the whole text could considerably be shortened if only those four paragraph initial sentences were read and the rest were skipped (to put it very provocatively).

One last very important feature of the structure of the connective relationships is their surface marking. A glance at how many connective relationships are actually surface marked will reveal that about half are not marked at all. Even if we allow for the fact that some indication of the logical relationship is given by the lexical material contained in the sentences it seems a remarkable fact that such a high number of connective relationships are not indicated by surface markers. The question is how hearers or readers figure out what relationships do actually obtain (this being an important aspect of the comprehension of the text). After all, the hearer has to reconstruct the hierarchic structure of propositions together with the logical relationships between them such as given in the following graph:

I 1

$2-3$

contrast ("and then")

II 4

5-6 adversative ("But")

6-7 additive specifying

6-8 adversative $\theta$

III 9

10-11 additive-specifying

L11

10-12 contrastive (temporal) ("now")

(10-11)

$12-13 \theta$ additive specifying

$13-14 \theta$ additive specifying

13-15 contrastive (quite simply contrastive 
$15-16 \theta$ spec.

$16-17 \theta$ contrastive

\begin{tabular}{|c|}
\hline $\begin{array}{l}18 \\
19-20 \text { additive specifying } \theta \\
19 \\
(19-20) \text { - } 21 \text { causative } \theta \text { (conclusio) } \\
19-22 \text { additive ("Besides") } \\
\quad 22-23 \theta \text { spec. } \\
\quad 22 / 23-24: ?\end{array}$ \\
\hline
\end{tabular}

\section{Global text structures}

\subsection{Macrostructure}

One significant result of the analysis of the connective structure of the text has been that there are obviously propositions which are more important and others which are less important. It was pointed out that some sentences are dead ends in that they do not enter into connective relationships with the following sentences, on the one hand and, on the other hand, there are sentences which have a tremendous connective impact in that they enter into a relationship with whole sequences of following sentences. This uneven status of the propositions with respect to their connective relationships is of course the reflection of the unequal status of the individual sentences in a hierarchy of content. Recent text analysis such as conducted particularly by van Dijk has elaborated a concept of macrostructure which tries to capture the hierarchical status of the individual propositions. The theory of microstructures such as elaborated by van Dijk makes explicit the differential hierarchical status of the individual proposition in terms of their content and the relationship of propositions to each others. This hierarchical relationship of propositions to each other is normally represented in a tree structure.

$\mathrm{M}$-structure claims to predict what will be retained and what will be deleted from memory. Thus higher ranking propositions are likely to be more easily retained in memory versus lower ranking propositions or lowest ranking propositions which will probably not be retained at all. In summarizing, microstructure claims to determine summarizing behaviour in that propositions are being recalled to the extent that they are higher ranking rather than lower ranking in the text. There is plenty of evidence from psycholinguistic experimental literature that something like the construction of a macrostructure of the text actually goes on during and is part of the comprehension of a discourse, of any discourse. Since most material actually occurring on the textual surface is lost after seconds the problem is what determines what we retain in memory and how textprocessing in comprehension is steered. For instance, it has been shown that apart from the deletion of lower level material comprehension as textprocessing essentially entails construction and integration of lower ranking material into higher ranking material, i.e. into so-called 
macropropositions which are themselves hierarchically structured and which contain the lower levels of the macrostructure of the text.

The formation of the macrostructure in text processing constitutes a top down process in comprehension. At any point in the comprehension of a text the reader will already have formed macropropositions (and will have forgotten lower level propositions), which at this given point in the reading of the text will constitute expectations as to what will come next, and which will facilitate and speed up comprehension at this point. They are top down processes in that the reader brings to bear to the comprehension of surface material knowledge that is already present at this point and which is derived from prior text processing up to this point in the linearly proceeding cpmorehension of the text.

In concrete terms, the macro-structure of the individual paragraphs of the text analysed would have to be represented as in Diagram 2.
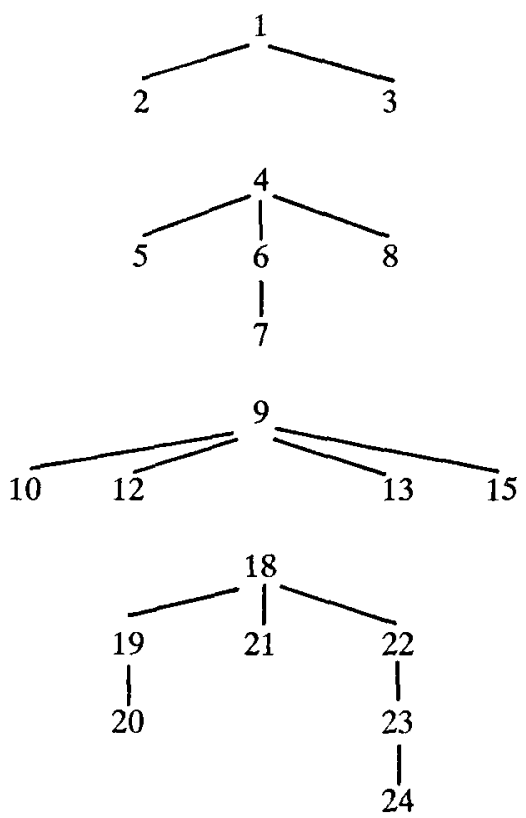

Diagram 2: Macro-structure of sample text (cf. appendix; numbers refer to sentence numbering in appendix text)

It can be seen that the macro-structure makes explicit the different status of propositions in a hierarchy of content: if the content had to be condensed, as in a summary, the lower levels would be pruned. The psycholinguistic correlate of this hierarchical structure is that the sentences with lowest status would be forgotten most easily. Depending on the level of explicitness required, the cut-off point would move higher up. Roughly, there are four levels of propositions, with the lowest ones probably to be forgotten at once. To these belong $20,23,14,16,17$. These concern subsidiary details. 
Still further below would be clauses which were not marked as clauses in their own right in the first place, such as the first clauses of 11,20 , and 13 ("or so ... ").

If the higher propositions like $10,12,15,19,21,23$ act as macropropositions, the highest level is certainly represented by the first sentences of the paragraphs $(1,4,9,18)$. In a high degree of text condensation, these sentences can surely be considered as encapsulating the "gist" of the text. Skip-reading the text could certainly be defined as reading only those four sentences. These four "topical" sentences as macropropositions of the text are hierarchically structured in the same way as the paragraphs are internally (see Diagram 3).

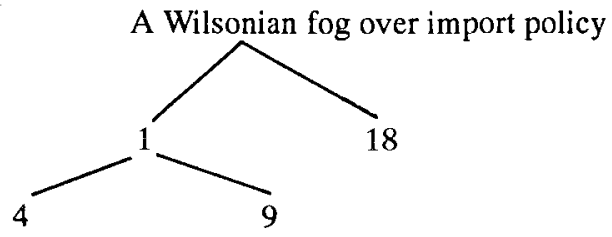

Diagram 3: Macro-structure of paragraphs and macropropositions (with headline as highest macroproposition)

In this diagram IV is set off from II and III since this paragraph as a whole is in causative relationship to the whole of II and III, which are betrween each other in an additive relationship. I stands apart, it kind of "tables the question," it acts as exposition.

Finally, as a theoretical point, it should be mentioned that $\mathrm{m}$-struture theory postulates that there may not be in principle an isomorphism between the propositions represented on the text surface and the macropropositions postulated. In theory, it is quite possible that, by the operation of so-called "macro-rules," information is condensed, transformed and integrated in a way that macropropositions do not conform to any of the propositions encountered in the text. In the present text, however-and this represents a significant fact for the interpretation in the next section-it is quite clear that the paragraph-initial sentences in the text come very close to what would have to be considered the macropropositions of the individual paragraphs, i.e. the macrostructure can easily be read off the surface of the text.

With reference to the properties of the cohesive relationships as analysed in the preceding section, particularly the differential status of the propositional macrostructure can account for nonadjacent connective relationships. For instance it would specify that sentence 7 is at a dead end in a tree structure and not connected through one node to 8 whereas 6 is connected to 8 via one node.

\subsection{Superstructure}

The preceding discussion of macrostructure has in various places suggested terms like arguments, reasons, and so forth for which the notion of macrosiructure has no conceptual 
tools with which to handle it. On the other hand, the connective relationships described are of a nature that suggest describing the text as dialectic or rhetorical or agonistic in character. In other words, it is obvious that what we have before us is an argumentative text in which arguments are displayed or a case is made for or against a certain view. However, such terms like "arguments" are not part of what marostructure can handle. Rather, terms like "arguments" are part of a superstructural analysis of discourse which analyses parts of discourse in functional terms. Propositions, sentences, and macropropositions "function" or "count" as arguments. In other words, readers and hearers obviously interpret sentences or clusters of sentences as arguments without them being explicitly, on the textual surface, told to do so. Obviously, the reader has pre-existing knowledge of what functional categories to expect in a given piece of discourse. By "preexisting" is meant that this type of knowledge and expectation as to the superstructural slots is present or "switched on" as soon as the reader knows he is facing a leader article. The discourse at hand can be classed as a leader article in an English weekly newspaper, The Guardian Weekly, and as such is of an argumentative nature. In such a text, the reader will expect opinions to be displayed, reasons for the opinions to be given, and cases to be made for or against opinions. He will also expect his comprehension to be guided by topical sentences. In other words, in the discourse type at hand the reader will expect to be displayed and is therefore ready to interpret sentences as representing certain structural or functional categories such as an argument. In other words, the reader will have prior knowledge as to the so-called "text schema."

Schemata go with frames, scripts in representing cognitively given and conventionally co-occurring pieces of knowledge about the world. Discourse types, to the extent that they can be characterized as schemata, will have definitional functional slots. The classical example for a text schema is the narrative text.

\subsection{Functional Sentence Perspective}

The status of the topical sentence has been discussed under the aspect of macrostructures (as macroproposition) as well as under the functional aepect, as part of the text schema. There is, however, another analytical level under which the topical sentence has a prominent role in this particular discourse and in this particular text type. Any discourse can be understood as a linearly proceeding unfolding or transmission of information. This aspect of linearity has been an inportant aspect in psycholinguistic arguing for the concept of a macrostructure, especially in the transformation of a linear surface structure into a hierarchic structure as the end product of comprehension stored in some form in memory. On a more local level, it is obvious that the topical sentence creates some sort of a tension, an expectation that more specific information will be supplied. It has a forward-looking, cataphoric effect. While pro-formation is, as a rule, backward-looking, i.e. anaphoric, the topical sentence is both, including an important cataphoric aspect. It therefore has an important two-way cohesive function.

With regard to the local "expectation-creation" as another form of textual coherence, if the expectation would not be satisfied a feeling of dissatisfaction, of non-integratedness would remain. After all, the task of discourse linguistics is, as was stated at the outset of 
this paper, the explication of the linguistic means that give us an intuitive feeling of integratedness, wholeness, and sensefulness.

In terms of macrostructure this cataphoric effect constitutes a top-down process, in that it contextualizes the comprehension of the linearly following surface material. This is, of course, only true if the macrostructure does actually occur in the text, as it does in the presently analysed text and text type.

There is something of a paradox of the same phenomenon working in two directions with respect to two different mechanisms at work in the very same process of textcomprehension. What on the local level of real-time reading of the surface text is a comprehensional and psychological necessity, i.e. the supplying of detailed specifying information, is, on the global, text processing level, exactly what will be deleted and forgotten in the formation of the macrostructure as the stored end-product of text processing. This dual aspect of text processing is reflected in the linguist activity in establishing - at least-two levels of analysis. However, it must not be forgotten that what the linguist performs after one another and seemingly separately, happens simultaneously unconsciously in the mind of the reader, in an incredibly short time. This is why there must be short cuts in terms of pre-existing information, like top-down processes instantiated by topical sentences.

This feeling of necessary introduction of new material triggered by a "superordinate" sentence is made explicit by the theory of Functional Sentence Perspective, such as elaborated by the Prague School of Linguists and briefly sketched above in $\S 2$.

It is not appropriate here to offer a Functional Sentence Perspective analysis of the whole text, but it should be pointed out that the topical sentence involves a typical and specific pattern of thematic progression, i.e. the development of content from a given point of departure. Paragraph-initial sentences introduce in their rhematic part new content that is made the point of departure for the following sentences. Thus at the beginning of paragraph two the uselessnes of import controls in the face of the latest gloomy trade figures is put on the table, it is the new information, the rheme. The theme (already present information) is just "import controls." The folling sentences all derive their themes-with whatever new/rhematic material they are introducing-from this "hypertheme," although in a very indirect, non verbatim way. They would not be comprehensible, or make no sense without the "hypertheme" of the paragaph being introduced in the first sentence of the paragraph. This is the meaning FSP gives to what has been described as the cataphoric effect of the topical sentence: the themes of the following sentences are derived from the-logically prior-rheme of the topical sentence. Try to imagine the following sentences standing alone without the first sentence.

The topical sentence has also the effect of a change of topic and topic entities, in terms of things and objects talked about. This is related to FSP, but it is not the same thing, nor is it the same thing as $\mathrm{m}$-structure, although it is very related to this, too. Topic entities are related to each other by anaphoric chains and by semantic (seme) isotopies. They only refer to entities talked about, not to propositions, which are larger units, and which logically contain or include topic entities. It is possible to assign individual topics to each paragraph in the same way in which topics can be assigned to each sentence. As a rule, for each sentence, the theme is identical with the topic. 
In all of the paragraphs, the topical sentence effects a change of topic. This is brought out in the macrostructure on the paragraph level by the logical relationship "contrastive": since the macrostructure on this level would indicate contrastive relationships, as a corrollary, this implies-in this text type, but not necessarily universally-a change of topic and topic entities.

\section{Text type: persuasion and subjectivity}

It was noted above that the text investigated is a leader article with a concommitent text schema. The feature that is most saliently characteristic of this genre was the type of connections observed, i.e. contrative, rhetorical, agonistic (with causative connective relationships in the conclusio in the last paragraph). However, the rhetorical contrastive argumentative structures do not exhaust the characteristics of this text type. They are the elements most directly relatable to the function of this text. To characterize text types, recourse is often being made to the categories of speech act theory, in particular to the types of elocution associated with individual utterances, such as directive, expressive, performative, representative, commissive etc. Although these illocutionary types (Searle, for a good and readable exposition see Traugott and Pratt) have been predicated upon individual sentences or utterances, the notion has been extended to apply to whole types of a discourse, such that a whole genre or a discourse type is said to be directive or expressive or performative or commissive in nature. The directive speech act wants to effect a change in the actions or opinions of the intended recipient, as is the express intention of the leader article.

While the contrastive rhetorical structure goes with the directive aspect of the leader article there is another component of the leader article which is just as important as its directive, i.e. opinion changing, feature, which is the expressive side. By "expressive" is essentially meant the expression of speaker attitudes, more precisely the speaker's subjective evaluation. Jones has pinpointed expressive and subjective elements in his examplary analysis of texts.

In the text under analysis here, which are the subjective/evaluative features which are typical for the expressive aspect of this text? It is possible to identify a number of types of features.

1. Evaluative metaphors: "ramble," "muddy the water," "stop the rot," "the trouble," "to dream up," "to blow money." All of these expressions contain a subjective view of what is described. The events are not described in themselves by the normal referential expressions but they are being commented on by the use of metaphorical vehicels.

2. Evaluations inherent in the referential semantics of full lexical items: "studies ambiguity," "famous," "worrying," "began by saying," "categorically," "appears to," "shamefully," "quite simply," "besides," "even." While these expressions are not metaphors, they still contain in their semantics built-in elements of subjective evaluation in various, and in part subtle ways. For instance, the adjective "famous" contains an objective speaker evaluative element in that something is famous always from the point 
of view of the speaker. Expressions like "besides" or another one like "quite simply" is subjective in that they predicate a speaker judgement or a speaker evaluation on the ranking of importance of elements that are being reported in the text and this ranking is clearly a ranking from the side of the speaker. The same applies to expressions like "categorically" or "appear" or "began by," etc. An expression like "even" implies evaluation of events or reports in that some of these events are being valuated as more important or higher ranking than others. All these elements are evaluations from the speaker perspective which are built into the semantics of these expressions, in the same way as certain other expressions have a "deictic" component built in to their lexical semantics. Such expressions are for instance "here" or "there," or "now" or "then" which always relate to the respective speaker's time or place. It could even be argued that these subjective expressions are deictic in the sense that they have the speaker position built into them. As a final example the term "shamefully" should be mentioned, which is nothing else but a speaker or in this case writer, pronouncement that the events reported are, in his view, "shameful."

3. An expression like "or so exporting firms report" in paragraph III is subjective in an interesting way. It represents a distancing from the side of the writer of the text from what he is reporting. It makes the reader aware of a subjective position of the writer towards what he is saying. He is moving a little away from what he is saying. He is in fact saying it may not be quite true. In other words, he is commenting on what he is reporting. To that extent the writer makes his subjective position and subjective view to what is being reported quite transparent. Something like this could never happen in a news report where the author of the text fully identifies himself with the text and with the truth of what he reports.

4. In a very complicated way subjective elements are inherent in certain syntactic structures. Without diving too far into this matter it should just be said that a cleft sentence like in paragraph II "It is that import controls would not do much to stop the rot," or at the beginning of paragraph IV "To introduce protective measures now ... " would be silly and self-defeating, an extraposition. It is by now well known that these syntactic movement structures of deviations from canonical word orders are marked structures and carry certain discourse functions related to topicalizations or focussings, which always contain syntactive evaluative element.

\section{Prospects and further questions}

From what has been discussed there arise interesting questions for a contrastive linguistics. First of all, it might be asked whether the same text schemas are present in all languages or in comparable cultures, such as English, German and Italian. To the extent that schemas are cultural artefacts, there may indeed be differences. For instance one might well assume that a schema "leader article" exists in all three cultures in a comparable way. But given that assumption, it might be asked whether the same structural slots are present, and in the same relation to each other. It might be the case that not all slots must be present, or that other structural parts are also present in one, but not in the other. To go one step further, 
it might not be the case that the rhetorical structure manifested in the contrastive connective relationships is the same in all languages. Different cultures may have different conventions and traditions.

\section{Appendix}

For convenience of reference the text to be analysed in detail will be divided in numbered sentences. Thus, paragraph I contains sentences 1,2 , and 3 , and paragraph IV contains sentences $18-24$.

\section{A Wilsonian Fog over Import Policy}

I ${ }^{1)}$ In his ramble around the economic situation last week, the Prime Minister again broached the subject of import controls with studied ambiguity. ${ }^{2)}$ As in his famous interview in Newsweek earlier this summer, he began by saying categorically that import controls were dangerous and damaging - ${ }^{3)}$ and then muddied the water by adding, "I do not rule out protective measures for particular industries suffering serious injury as a result of increased imports."

II ${ }^{4)} \mathrm{But}$ if one thing is clear from the latest gloomy trade figures it is that import controls would not do much to stop the rot. ${ }^{5}$ If one compares the past two three-month periods, imports appear to have risen quite sharply. ${ }^{\circ}$ But the rise has not been in finished manufactures, the category where import controls would presumably be concentrated. ${ }^{7}$ Even the volume of imported cars and other transport equipment fell between the two periods. ${ }^{8}$ The increase has been concentrated in fuels, in chemicals, and in food, beverages and tobacco.

III ${ }^{9}$ The fall in exports is more worrying than the rise in imports. ${ }^{10}$ In the first half of this year, exports grew stronlgy. ${ }^{11)}$ Firms which at last found themselves with spare capacity on their hands managed to catch up on export backlogs, some of them stretching back shamefully far into 1973. ${ }^{12}$ Now as recent surveys by the Conferedation of British Industries have been revealing, new orders have petered out. ${ }^{13}$ The problem is not the basically one of price competitiveness - or so exporting firms report. ${ }^{14)} \mathrm{UK}$ inflation has been largely offset by declining value of the pound abroad. ${ }^{15}$ The trouble is quite simply the international slump. ${ }^{16)}$ In the past three months, only exports to the OPEC countries, where British firms have at last started to do as well as their tougher competitors, have really increased strongly. ${ }^{19}$ Exports to North America have fallen by 10 per cent.

IV ${ }^{18}$ To introduce "protective measures" now except in cases where dumping can be strictly proved under the rules of international trade, would be silly and self-defeating. ${ }^{19}$ ) Other governments in other industrial countries are under just the same sort of pressures as Mr. Wilson. ${ }^{20}$ Last week, the US Treasury was told to start investigating the dumping of cars on the American market and the protection lobby in the US is particularly worried about Volkswagen and British Leyland. ${ }^{21}$ Curbs on Japanese car imports into Britain would make it harder for the US administration to resist curbs on British car imports into America. ${ }^{2)}$ Besides, Britain already has as tough a set of import controls as the Department of Trade would dare to dream up. ${ }^{23}$ It is the $£ 6$-a-week pay policy. ${ }^{24)}$ With the fall in living standards 
that will take place this autumn, consumers are hardly going to have money to blow on imported luxuries.

The Guardian Weekly 20/9/75

\section{Works Cited}

Allerton, D. J. "Some Textually Relevant Grammatical Choices." The Structure of Texts. Ed. Udo Fries. Tübingen, 1987.

Antos, Gerd. Grundlagen einer Theorie des Formulierens: Textherstellung in geschriebener und gesprochener Sprache. Tübingen: Niemeyer, 1982.

Beaugrande, Robert-Alain de, and Wolfgang Dressler. Einführung in die Textlinguistik. Tübingen: Niemeyer, 1981.

Beaugrande, Robert-Alain de. Text, Discourse and Process: Towards a Multidisciplinary Science of Texts. Hillsdale: Erlbaum, 1980.

Coseriu, Eugenio. Textlinguistk: eine Einführung. Tübingen: Narr Verlag, 1980.

Dijk, T. A. van and Walter Kintsch. Strategies of Discourse Comprehension. New York, 1985.

Garvin, Paul. A Prague School Reader on Aesthetics, Literary Structure and Style. Sel. and trans. Paul Garvin. Washington: Georgetown UP, 1964.

Gerzymisch-Arbogast, Heidrun Zur Thema-Rhema Gliederung in amerikanischen Wirtschaftsfachtexten. Tübingen: Narr Verlag, 1987.

Halliday, M. A. K., and Ruqaiya Hasan. Cohesion in English. London: Longman, 1976.

Jens, Walter. "Rhetorik." Reallexikon der deutschen Literaturgeschichte. Ed. Werner Kohlschmidt. Berlin: de Gruyter, 1977, III 432-56.

Jones, Larry Bird. Pragmatic Aspects of English Text Structure. Arlington: U of Texas, Diss., 1984.

Searle, John R. Speech Acts: An Essay in the Philosophy of Language. Cambridge UP, 1969.

Traugott, Elizabeth, and Marie-Louise Pratt. Linguistics for Students of Literature. San Diego: Harcourt and Brace Jovanovich, 1980.

Weinrich, Harald. Sprache in Texten. Stuttgart: Klett, 1976. 